\title{
Kinerja Ghe Vent Dryer Dengan Menggunakan Lilin Sebagai Penyimpan Panas
}

\author{
(Performance Of Ghe Vent Dryer By Using Wax As Heat Storage)
}

\author{
Afdhalul Ahmar ${ }^{1}$, Mustaqimah $^{1}$, Diswandi Nurba ${ }^{1}$ * \\ ${ }^{1}$ Program Studi Teknik Pertanian, Fakultas Pertanian, Universitas Syiah Kuala \\ *Corresponding author: diswandinurba@unsyiah.ac.id
}

\begin{abstract}
Abstrak. Green house effect (GHE) vent dryer adalah alat pengering dengan memanfaatkan energi surya sebagai sumber energi pengeringan. Namun radiasi matahari terbatas pada waktu tertentu sehingga mengganggu prases pengeringan. Penambahan lilin sebagai media penyimpan panas adalah salah satu solusi agar alat green house effect (GHE) vent dryer dapat beroperasi pada saat energi surya sudah meredup. Tujuan penelitian ini untuk menguji kinerja GHE Vent Dryer dengan menggunakan lilin sebagai media penyimpan panas. Data yang diukur dalam penelitian ini berupa suhu di dalam ruang pengering (ruang 1, ruang 2 dan ruang 3), ruang absorber, suhu lingkungan dan kecepatan udara. Pengukuran dimulai dari pukul 08.00 WIB sampai sahu didalam ruangan menyamai suhu lingkungan, proses pengukuran dilakukan setiap 60 menit. Hasil penelitian ini didapatkan bahwa rata-rata suhu absorber menggunakan lilin sebagai media penyimpan panas berkisar $31{ }^{\circ} \mathrm{C}$ sampai $71{ }^{\circ} \mathrm{C}$ dengan temperatur lingkungan yang di hasilkan $27^{\circ} \mathrm{C}$ sampai $35^{\circ} \mathrm{C}$ dan untuk terperatur dalam alat pengering sekitar $27^{\circ} \mathrm{C}$ sampai $58^{\circ} \mathrm{C}$. Hasil pengukuran kecepatan udara pada penelitian ini berkisar $0,3 \mathrm{~m} / \mathrm{s}$ sampai $1,5 \mathrm{~m} / \mathrm{s}$. Dapat disimpulkan bahwa penggunaan batu serpihan sebagai media penyimpan panas pada alat GHE vent Dryer mampu mempertahankan panas pada ruang pengering selama 4 sampai 5 jam saat tidak ada radiasi matahari.
\end{abstract}

Kata Kunci: green house effect (GHE) vent drey, lilin, radiasi, suhu.

Abstract. Green house effect (GHE) vent dryer is a dryer that uses solar energy as a drying energy source. However, solar radiation is limited to a certain time so that it interferes with the drying process. The addition of wax as a heat storage medium is one solution so that the green house effect (GHE) vent dryer can operate when the solar energy has dimmed. The purpose of this study was to test the performance of the GHE Vent Dryer using wax as a heat storage medium. The data measured in this study were the temperature in the drying chamber (room 1, room 2 and room 3), absorber chamber, ambient temperature and air velocity. The measurement starts from 08.00 WIB until the temperature in the room equals the ambient temperature, the measurement process is carried out every 60 minutes. The results of this study found that the average temperature of the absorber using wax as a heat storage medium ranged from $31 \mathrm{C}$ to $71 \mathrm{C}$ with an ambient temperature of $27 \mathrm{C}$ to $35 \mathrm{C}$ and for a temperature setting in the dryer it was around $27 \mathrm{C}$ to $58 \mathrm{C}$. The results of air velocity measurements in this study ranged from $0.3 \mathrm{~m} / \mathrm{s}$ to $1.5 \mathrm{~m} / \mathrm{s}$. It can be concluded that the use of crushed stone as a heat storage medium in the GHE vent Dryer is able to maintain heat in the drying chamber for 4 to 5 hours when there is no solar radiation.

Keywords: Green House Effect (GHE) Vent Dryer, Paraffin, Radiation, Temperature.

\section{PENDAHULUAN}

Pengeringan merupakan suatu proses pengurangan kadar air yang terkandung dari suatu bahan untuk aman di simpan pada pemanfaatan lebih lanjut. Pengeringan dapat dilakukan menggunakan cara alami (penjemuran) ataupun cara buatan artificial draying 
(Gunasekaran, 2012). Pengeringan dengan cara penjemuran salah satu cara yang sangat mudah dilakukan dan biayanya yang murah tetapi pengeringan alami ini memiliki banyak kekurangan karena pada saat pengeringan membutuhkan lahan yang luas dan mudah terkontaminasi dengan bahan asing. Alat pengering GHE Vent Dryer memanfaatkan energi matahari sebagai sumber energi, namun keterbatasan waktu radiasi matahari menjadi kendala dalam penggunaan GHE Vent Dryer, penggunaan media penyimpan panas pada bagian absorber GHE Vent Dryer menjadi sangat solutif. Lilin adalah salah satu bahan yang dapat dijadikan lilin merupakan hidrokarbon jenuh dengan rantai terbuka dan merupakan senyawa alkana. Parafin adalah campuran dari alkana (ikatan rantai molekul atom karbon dan hydrogen yang panjang), yang terdapat di dalam minyak bumi. Lilin akan meleleh pada suhu 40 sampai $50{ }^{\circ} \mathrm{C}$. Lilin adalah suatu campuran dari hidrokarbon yang dipenuhi massa molekular yang tinggi, diproduksi selama penyulingan dari minyak/petroleum. Lilin terbaru dari petroleum, memiliki nilai yang paling komersial (Fatimah,2008).

Sumber energi tambahan yang banyak diintegrasikan pada pengering surya adalah energi biomassa dari tungku dan kolektor surya. Kolektor surya merupakan sesuatu alat yang berfungsi untuk mengumpulkan energi matahari yang masuk dan diubah menjadi energi thermal dan meneruskan energi tersebut ke fluida (Priadi, 2008). Kolektor plat datar pada umumnya digunakan untuk menghasilkan temperatur fluida kerja yang rendah, dan sudah diproduksi secara masal untuk kebutuhan rumah tangga (Darwin dan Thaib, 2010). Jika lilin dipanaskan, akan terjadi perubahan - perubahan nyata pada dua titik suhu. Lilin mudah di bentuk dari padat ketika di panaskan akan melelah menjadi cair dan akan kembali padat ketika di dinginkan lilin mencair jika dipanaskan. Karena lilin adalah campuran trigliserida mereka tidak mempunyai titik cair yang jelas tetapi akan mencair pada suatu rentang suhu. Suhu pada saat lilin terlihat mencair disebut titik lincir. Kebanyakan lilin mencair pada suhu antara $30^{\circ} \mathrm{C}$ dan $40^{\circ} \mathrm{C}$ (Rahadian, 2009). Titik cair lilin adalah di bawah suhu udara biasa. Nilai konduktifitas lilin adalah 0,02 (Zemansky, 2002), dan penggunaan lilin sangat cocok digunakan pada GHE vent dryer.

\section{METODE PENELITIAN}

Alat dan bahan yang digunakan dalam penelitian ini adalah Green House Effect (GHE) Vent Dryer, , Termometer, Anemometer, Absorber, Solarimeter, Humiditymeter dan alat pendukung lainnya. Bahan yang digunakan Lilin.

\section{Prosedur Penelitian}

Disiapkan lilin kemudian ditimbang sebanyak $9 \mathrm{~kg}$, setelah dilakukan penimbangan kemudian lilin dipanaskan hingga mencair untuk dimasukkan ke dalam pipa tembaga yang sudah disiapkan sebanyak 9 pipa dengan panjang pipa $100 \mathrm{~cm}$ dengan volume lilin yang di isi sebanyak $1 \mathrm{~kg}$ per pipa. Kemudian penelitian dimulai dari pukul 08.00 sampai 22.00 WIB. Pengecekan Radiasi menggunakan alat Humiditymeter yang diletakkan didekat alat GHE Vent Dryer, pengecekan suhu menggukan Termometer pada $\mathrm{T}$ ruang pengering, $\mathrm{T}$ Linglungan, $\mathrm{T}$ absorber dan $\mathrm{T}$ outlet dapat dilihat pada Gambar 1, pengecekan aliran udara menggunakan Anemometer. Adapun mekanisme kerja dari lilin adalah menyerap panas yang dihasilkan oleh radiasi surya kemudian menyimpan panas tersebut pada saat radiasi surya mulaimeredup lilin akan mengeluarkan panas yang telah disimpan dan membuat ruang GHE Vent Dryer tetap di atas suhu lingkungan. 


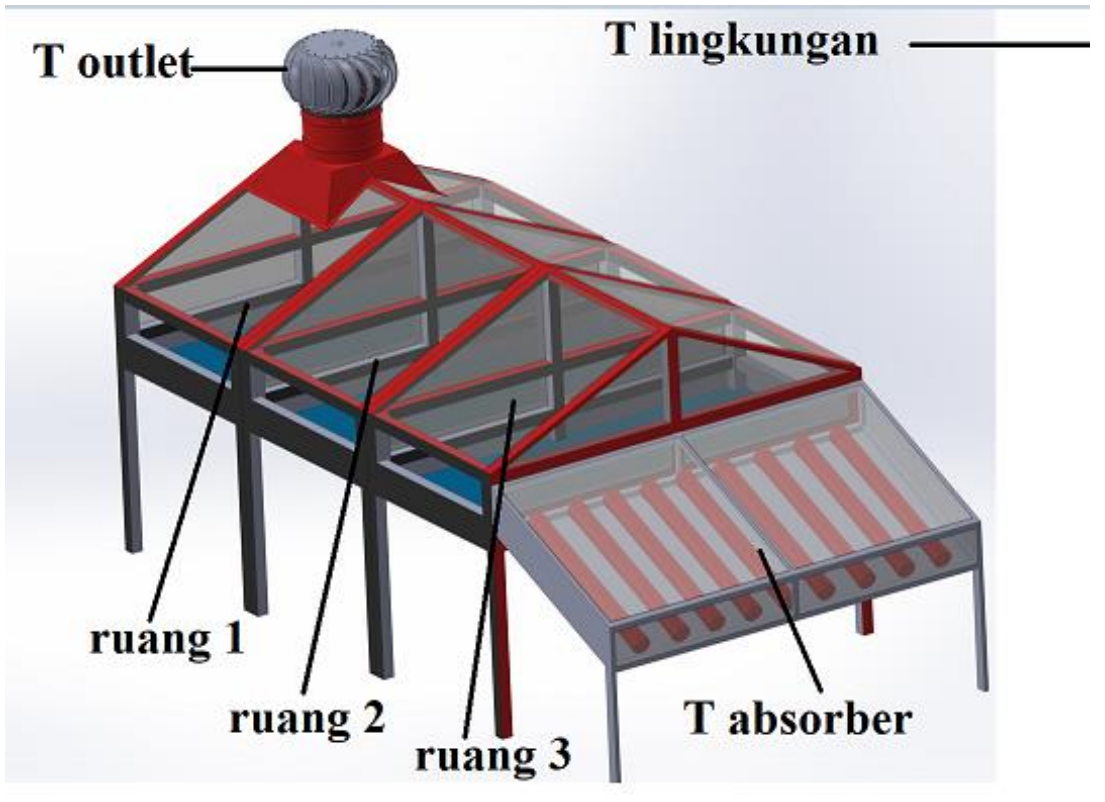

Gambar 1 . Titik-titik Pengukuran

\section{Deskripsi alat Green House Effect (GHE) Vent Dryer}

Konsep perancangan alat pengering GHE vent dryer mengikuti konsep pengeringan tipe terowongan. Alat pengering GHE vent dryer ini dilengkapi dengan absorber yang terbuat dari plat seng dan diwarnai dengan warna hitam. Absorber ini berfungsi untuk menyerap panas matahari dan diteruskan ke dalam ruang pengering. Alat pengering ini terbuat dari kaca akrilik $5 \mathrm{~mm}$ yang transparan sehingga terjadilah konsep GHE vent dryer dalam alat pengering yang dirancang. Kincir savanious dipasang pada satu bagian atap yang berfungsi untuk menghisap uap air dalam ruang pengering sehingga proses pengeringan menggunakan GHE vent dryer dapat berjalan lebih singkat dibandingkan pengeringan konvensional. Ukuran alat ini 2,7 x 3,8 meter dan memiliki 6 rak dalam ruang pengering ( Yasar et al, 2020). Skema bangunan (GHE) Vent Dryer dapat dilihat pada Gambar 2.

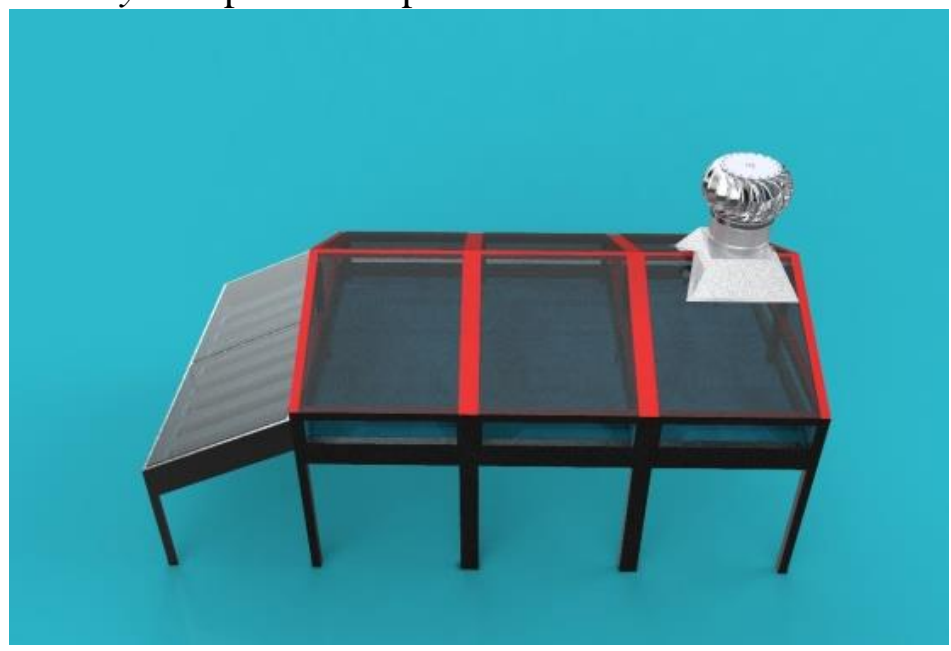

Gambar 2. Bangunan alat Green House Effect (GHE) Vent Dryer 


\section{HASIL DAN PEMBAHASAN}

\section{Distribusi Suhu Ruang Absorber dan Ruang Pengering}

Suhu pada ruang pengering saat pengujian ke 2 berkisar antara $25{ }^{\circ} \mathrm{C}$ sampai $61{ }^{\circ} \mathrm{C}$ dengan tingkat radiasi tertinggi terjadi pada jam 13.00 WIB dengan nilai radiasi mencapai 6,2 $\mathrm{W} / \mathrm{m}^{2}$. Sementara suhu lingkungan pada saat itu berkisar antara $37{ }^{\circ} \mathrm{C}$. Suhu ruang absorberpada jam 13.00 WIB mencapai $63{ }^{\circ} \mathrm{C}$ sedangkan suhu yang diperoleh dari ruang pengering pada ruang 1 mencapai $57^{\circ} \mathrm{C}$, kemudian pada ruang 2 mencapai $57^{\circ} \mathrm{C}$, dan pada ruang 3 mencapai $59^{\circ} \mathrm{C}$. Pada pengujian penyimpan panas bekerja dengan efektif dikarenakan temperatur ruang pengering lebih tinggi dibandingkan dengan temperatur lingkungan.

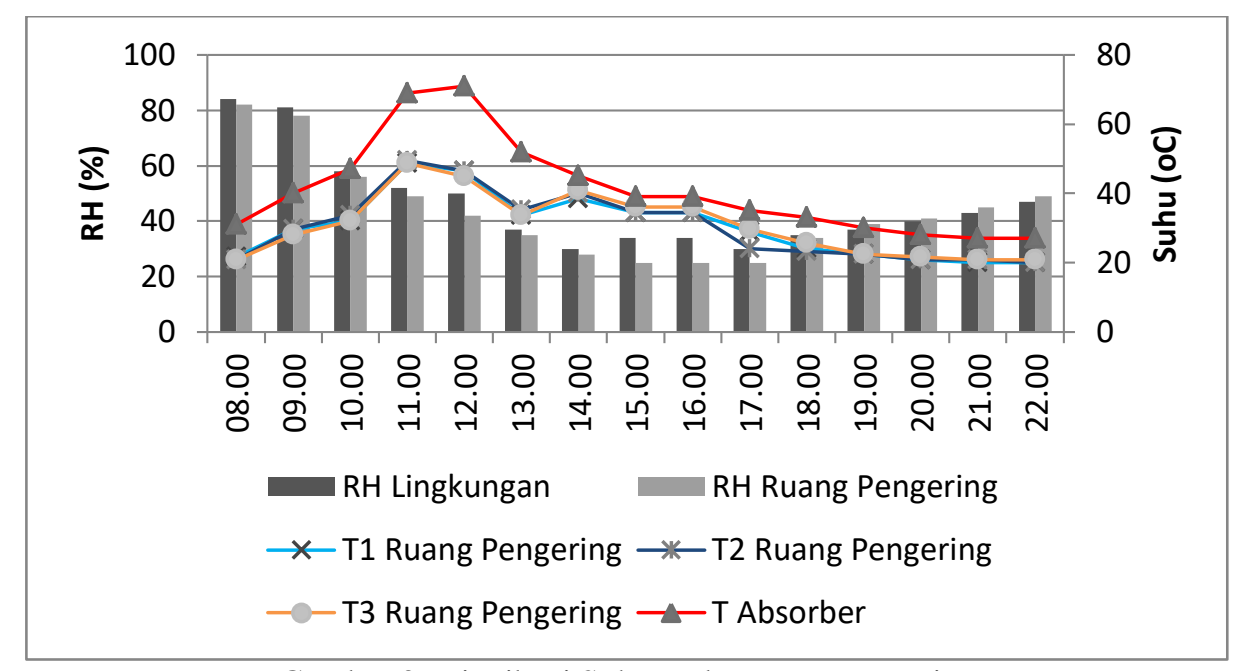

Gambar 3. Distribusi Suhu Pada Ruang Pengering

Pada Gambar 3 dapat dilihat bahwa suhu pengeringan memiliki pola yang relatif seragam terhadap waktu dibandingkan dengan suhu ruang pengering pada hari ke 1 yang di akibatkan oleh aspek lingkungan yang tidak menentu. Dari Gambar 3 di atas terlihat suhu pengering pada tiap waktu awal cenderung meningkat dan melebihi $5^{\circ} \mathrm{C}$ dari suhu lingkungan, hal ini disebabkan karena adanya tambahan panas dari radiasi surya, namun pada sore hari saat radiasi mulai berkurang, suhu di dalam ruang pengering mulai menurun dengan perlahan sehingga membuat suhu di dalam pengering perlahan menyamai suhu yang ada di lingkungan (Agustina, 2016).

Suhu lingkungan pada jam $08.00 \mathrm{WIB}$ yaitu $26^{\circ} \mathrm{C}$ suhu ruang absorber adalah $28^{\circ} \mathrm{C}$ suhu ruang pengering ruang 1 adalah $25^{\circ} \mathrm{C}$, ruang pengering ruang 2 adalah $26^{\circ} \mathrm{C}$ dan ruang pengering ruang 3 adalah $26{ }^{\circ} \mathrm{C}$ dengan radiasi pada saat itu mencapai $1,2 \mathrm{~W} / \mathrm{m}^{2}$.Suhu tertinggi pada pengujian adalah pada jam 13.00 WIB yaitu suhu lingkungan yang mencapai $37^{\circ} \mathrm{C}$ kemudian suhu ruang absorber adalah $63{ }^{\circ} \mathrm{C}$ dengan suhu ruang pengering ruang 1 adalah $57{ }^{\circ} \mathrm{C}$ ruang pengering ruang 2 adalah $57{ }^{\circ} \mathrm{C}$ dan ruang pengering ruang 3 adalah 59 ${ }^{\circ} \mathrm{C}$ dengan radiasi pada saat itu mencapai $6,2 \mathrm{~W} / \mathrm{m}^{2}$.

\section{Pengukuran suhu dengan Termometer}

Pengukuran suhu menggunakan termometer yang diletakkan dibeberapa titik $\mathrm{T}$ lingkungan $\mathrm{T}$ absorber, ruang 1 , ruang 2 , ruang 3 dan $\mathrm{T}$ outlet. Pengukuran pada penelitian ini dilakukan pada cuaca yang mendukung dimulai dari jam 08.00 WIB sampai dengan jam 22.00 WIB. Setelah data hasil pengukuran suhu didapatkan maka dicatat hasilnya dan diubah dalam bentuk grafik. Grafik dapat dilihat pada Gambar 4. 


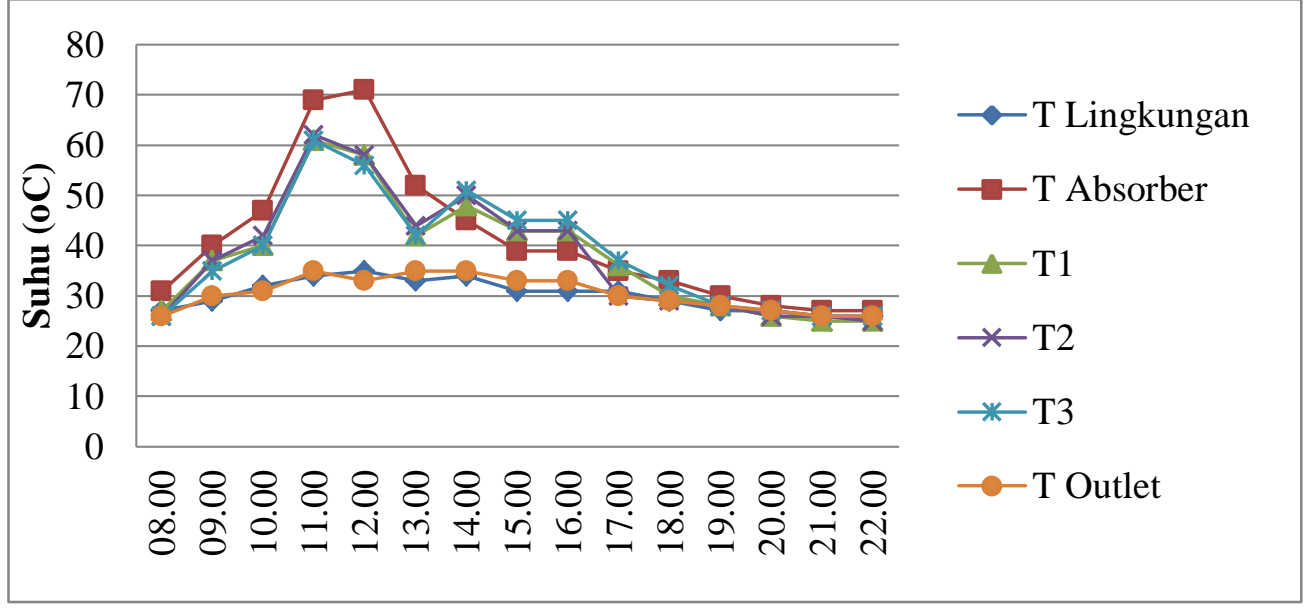

Gambar 4. Distribusi suhu absorber

Gambar 4 terlihat perbedaan suhu antara suhu ruang pengering dan suhu lingkungan dimana suhu ruang pengering cenderung lebih tinggi dibandingkan suhu lingkungan. Suhu ruang pengering memiliki suhu tertinggi pada jam 11.00 WIB yaitu pada ruang 1 adalah 61 ${ }^{\circ} \mathrm{C}$, pada ruang 2 adalah $62{ }^{\circ} \mathrm{C}$ dan pada ruang 3 adalah $61{ }^{\circ} \mathrm{C}$ dengan suhu di dalam ruang absorber mencapai $71{ }^{\circ} \mathrm{C}$ dan iradiasi mencapai $6,3 \mathrm{~W} / \mathrm{m}^{2}$. Kemudian suhu ruang pengering mulai menurun pada jam 17.00 WIB terdapat suhu ruang ruang 1 adalah $36^{\circ} \mathrm{C}$, suhu ruang ruang 2 adalah $30^{\circ} \mathrm{C}$ dan di ruang ruang 3 adalah $37^{\circ} \mathrm{C}$ dengan suhu absorber $31{ }^{\circ} \mathrm{C}$. pada jam 18.00 WIB sampai jam 22.00 WIB suhu absorber mulai menurun perlahan-lahan sehingga suhu di dalam alat pengering menyamai suhu yang berada di luar alat pengering. Pada jam 22.00 WIB terdapat suhu di didalam ruang ruang 1 adalah $25^{\circ} \mathrm{C}$, di ruang ruang 2 adalah $25^{\circ} \mathrm{C}$, di ruang ruang 3 adalah $26^{\circ} \mathrm{C}$, suhu absorber $26{ }^{\circ} \mathrm{C}$ dan suhu lingkungannya sudah menyamai suhu di dalam alat pengering sehingga pada jam 22.00WIB suhu sudah dikatakan konstan.

\section{Kecepatan Aliran Udara}

Pada Gambar 5, kecepatan aliran udara untuk pengeringan, kecepatan aliran udara luar menggunakan media penyimpan panas dapat dilihat pada Gambar 5, dimana laju aliran udara luar pada jam 08.00 - $12.00 \mathrm{WIB}$ mengalami peningkatan antara $0,2-0,5 \mathrm{~m} / \mathrm{s}$ hal ini di akibatkan oleh kendaraan besar yang melewati alat pengering diakibatkan oleh posisi alat pengering yang berada tetap bersampingan dengan jalan raya kemudian factor lingkungan dan iklim juga mempengaruhi kecepatan aliran udara, banyak proses yang perlu diperhatikan seperti iklim dan bahan baku yang mempengaruhi waktu dan perolehan pengeringan (Daulay 2005).

Perbedaan kelembaban lingkungan dan ruang pengering dapat dilihat dari grafik dibawah. Suhu kelembaban akan semakin turun sesuai dengan panas yang dihasilkan oleh radiasi surya. 


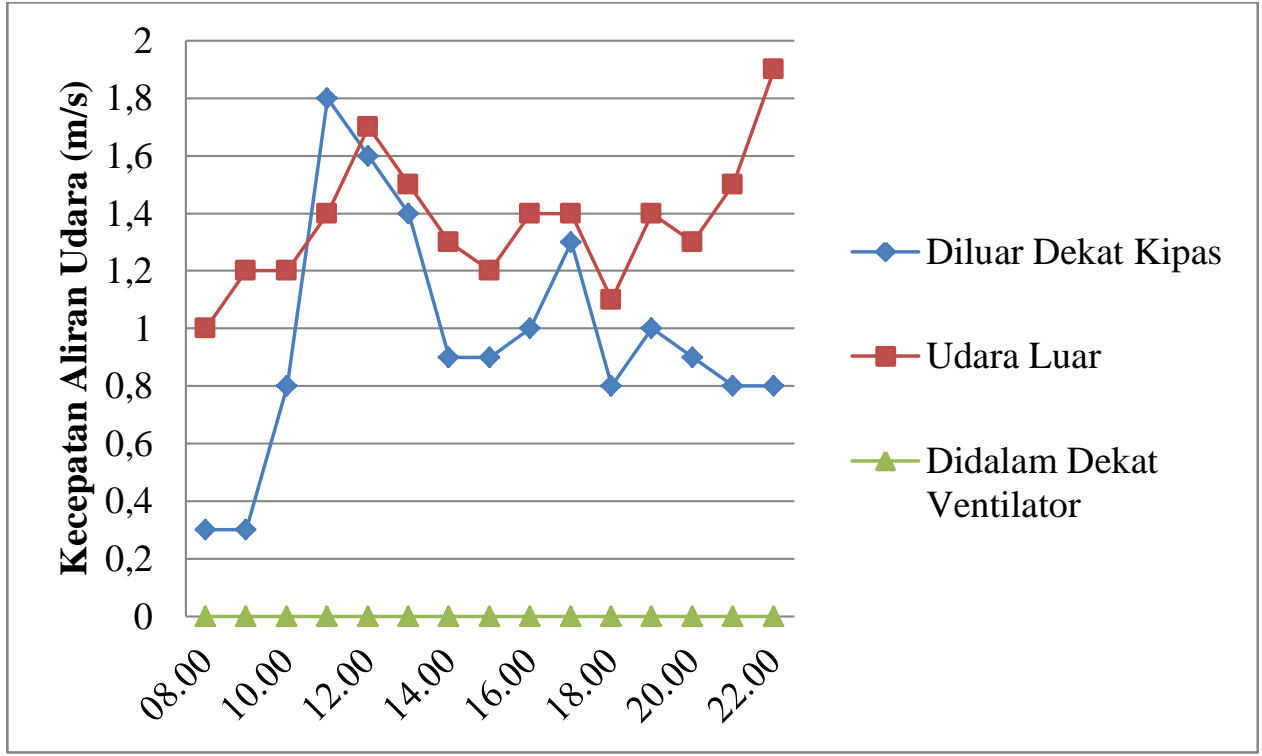

Gambar 6. Kecepatan Aliran

Untuk kelembaban nilai yang didapat ruang pengering adalah $83 \%$ yaitu pada suhu awal jam 08.00 WIB sementara terendah terjadi pada jam 15.00 WIB dengan kelembaban sebesar 35\%. Adapun ketidakteraturan kelembaban pada jam 14.00 - 17.00 WIB bisa dikarenakan kesalahan operator pada saat jam 13.00 WIB pintu ruang pengering terbuka terlalu lama untuk dilakukan penukaran bahan yang dikeringkan sehingga mempengaruhi nilai kelembaban. Untuk kelembaban relatif tertinggi pada lingkungan adalah $85 \%$ sementara terendah adalah $37 \%$. Hal ini sangat dipengaruhi oleh kecepatan aliran udara, pada prinsipnya pengeringan dipengaruhi oleh kecepatan aliran udara pengering, suhu udara pengering, dan kelembaban udara (Himawanto dan Najib 2003),. Kelembaban udara pada alat pengering dan lingkungan dihitung dengan menggunakan alat Humidity meter, selama proses pengeringan kelembaban (RH) akan mengalami fluktuasi seiring dengan fluktuasi yang terjadi pada besar kecilnya intensitas cahaya matahari, sehingga berpengaruh terhadap suhu udara dan mempengaruhi besar kecilnya kelembaban (Fekawati 2010).

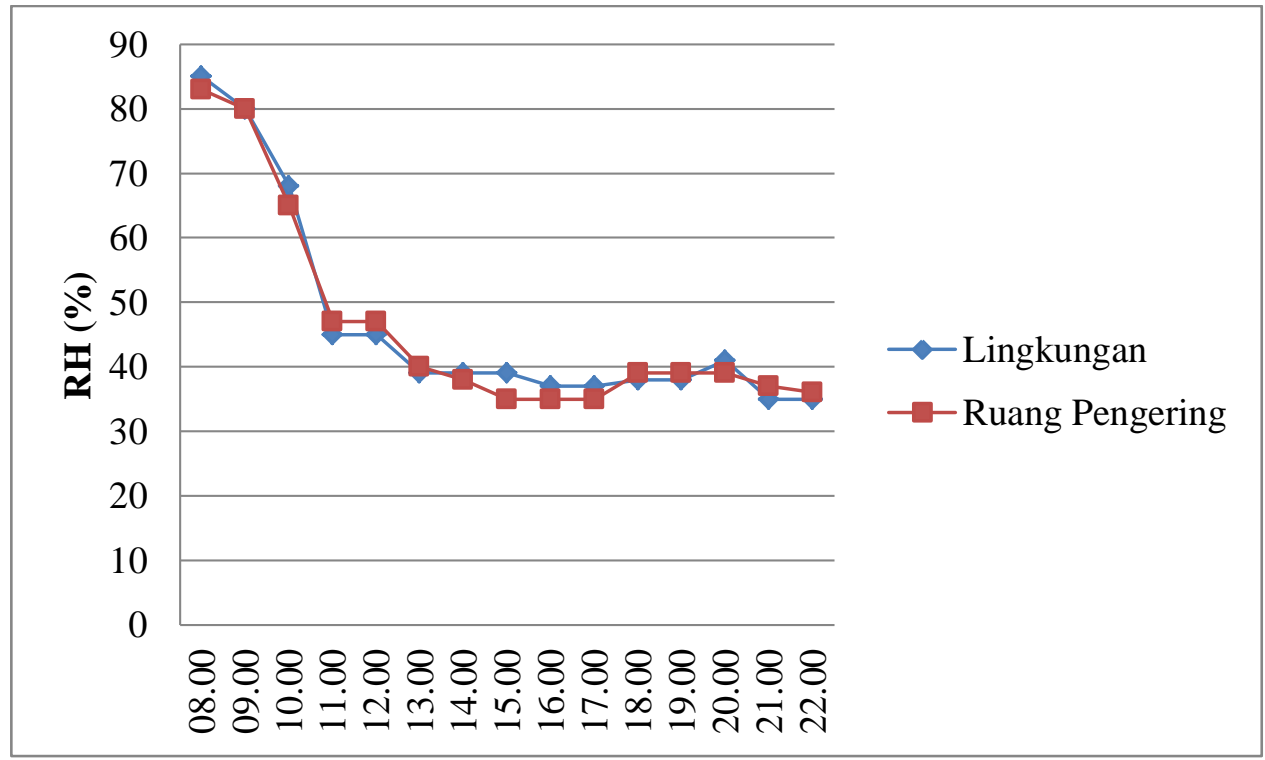

Gambar 7 . Kelembaban Udara 


\section{Radiasi Surya}

Berdasarkan Gambar 8 bahwa Pada jam 08.00 WIB terdapat iradiasi surya sebesar 1,2 $\mathrm{W} / \mathrm{m}^{2}$ dan pada ruang absorber diketahui suhu adalah $28{ }^{\circ} \mathrm{C}$, suhu iradiasi semakin naik sampai pada jam 13.00 WIB sudah diketahui suhu iradiasi mencapai $6,2 \mathrm{~W} / \mathrm{m}^{2}$ dan pada ruang absorber diketahui suhu mencapai $63{ }^{\circ} \mathrm{C}$, kemudian pada jam 14.00 WIB iradiasi mulai menurun hal ini dikarenakan pengaruh cuaca yang mulai mendung sehingga membuat radiasi menjadi berkurang, meskipun radiasi berkurang tidak akan berpengaruh pada suhu ruang absorber dikarenakan pada saat suhu lingkungan mulai dingin di saat itulah lilin mengeluarkan panasnya dapat dilihat pada grafik bahwa iradiasi pada jam 14.00 WIB adalah $4,1 \mathrm{~W} / \mathrm{m}^{2}$ sedangkan suhu ruang pengering masih mempertahankan panas dengan suhu absorber diketahui mencapai $55^{\circ} \mathrm{C}$. Suhu ruang absorber perlahan menurun sampai pada jam 22.00 WIB diketahui ruang absorber memiliki suhu $27^{\circ} \mathrm{C}$ sedangkan suhu lingkungan adalah $27^{\circ} \mathrm{C}$.

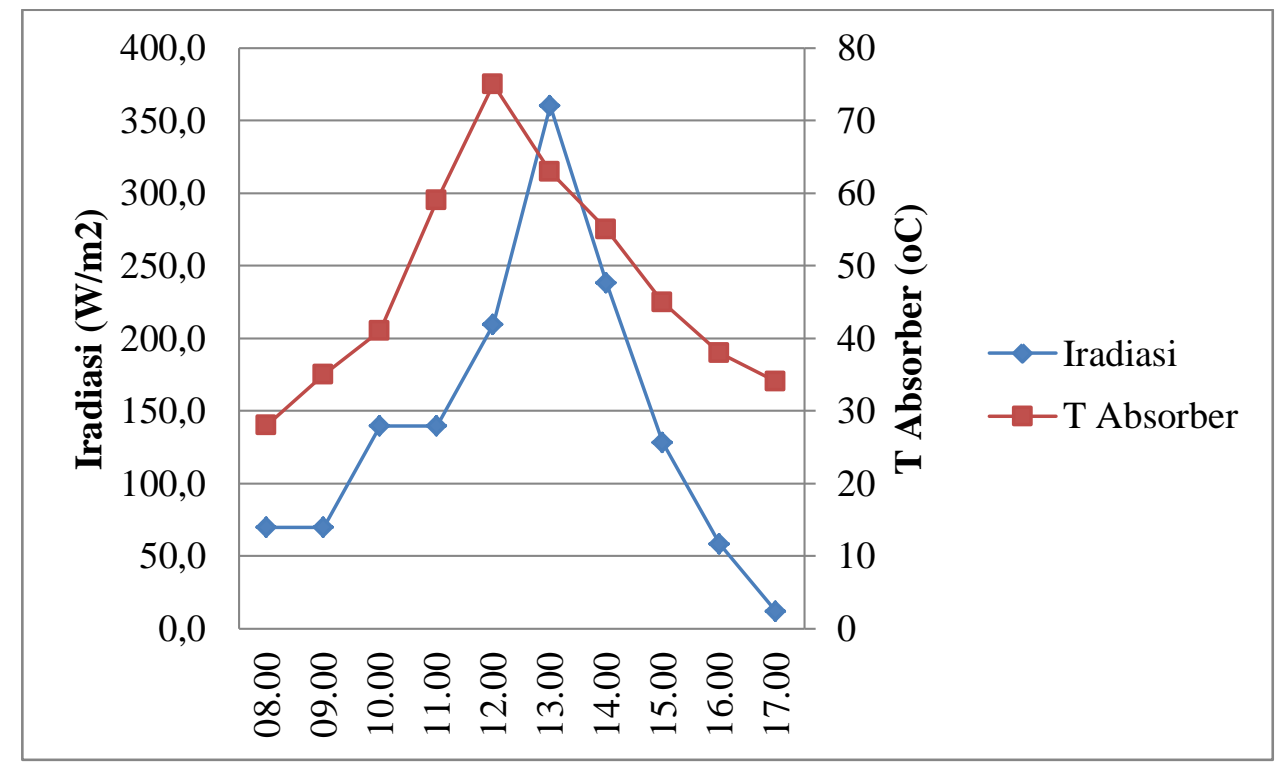

Gambar 8. Iradia Surya 


\section{KESIMPULAN DAN SARAN}

\section{KESIMPULAN}

Berdasarkan hasil penelitian dapat di simpulkan bahwa:

1. Total suhu ruang absorber adalah $71{ }^{\circ} \mathrm{C}$ dengan rata-rata suhulingkungan adalah $35{ }^{\circ} \mathrm{C}$ sedangkan suhu pada ruang pengering mencapai $62^{\circ} \mathrm{C}$.

2. Suhu plat penyerap, ruang absorber, media penyimpan panas, kaca penutup dan ruang pengering sangat dipengaruhi oleh radiasi surya dan suhu lingkungan, dimana suhu dapat berubah setiap detik karena pengaruh dari radiasi surya dan suhu lingkungan tersebut.

3. Kecepatan aliran udara sangat mempengaruhi proses penggerak ventilator guna mengeluarkan uap air dari dalam alat pengering GHE vent dryer sehingga proses pengeringan menjadi lebih cepat. Kecepatan udara didaerah penilitian berkisar antara 2 sampai $5 \mathrm{~m} / \mathrm{s}$.

4. Penggunaan media lilin sebagai penyimpan panas pada GHE vent dryer mampu mempertahankan suhu pada ruang pengering selama 4 sampai dengan 5 jam.

\section{SARAN}

Perlu dilakukan penambahan lilin untuk mempetahankan panas diruang pengering dalam waktu yang lebih lama.

\section{DAFTAR PUSTAKA}

Agustina, R., H. Syah., R. Moulana. 2016. Karakteristik pengeringan biji kopi dengan pengering tipe bak dengan sumber panas tungku sekam kopi dan kolektor surya. Jurnal Ilmiah Teknologi Pertanian AGROTECHNO. 1(1) pp:20-27.

Chandra, A., dan J.R.B. Witono. 2018. Pengaruh berbagai proses dehidrasi pada pengeringan daun Stevia Rebaudiana. Prosiding Seminar Nasional Teknik Kimia "Kejuangan" Pengembangan Teknologi Kimia untuk Pengolahan Sumber Daya Alam Indonesia.

Darwin dan R. Thaib. 2010. Pengaruh diameter tabung kaca dan pipa absorber terhadap performansi kolektor surya jenis silinder setengah lingkaran. Prosiding seminar Nasional Chesa (Chemical Engineering Science and Applications), Banda Aceh, 2223 Desemper 2010.

Daulay S. B., 2005, Pengeringan padi (metode dan peralatan), Jurusan Teknologi Pertanian Fakultas Pertanian Universitas Sumatera Utara. Jurnal Dinamika Teknik Mesin. Vol. 6. No. 2 hal 121.

Gunasekaran, K, Shanmugam, V. dan Suresh, P. 2012. Modeling and Analytical Experimental Study Of Hybrid Solar Dryer Integrated With Biomass Dryer For Drying Coleus Forskohli Stems. IACSIT Coimbatore Conferences IPCSIT.

Mustaqimah. 2019. Modification and performance test of fish and keumamah dryer with solar energy sources. IOP Conf. Ser : Earth Environt. Sci. 365 012044. 1-5.

Priyadi. 2006. Rancang bangun kolektor surya sebagai sumber energi alternatif masyarakat kota Bengkulu. Lab. Penelitian. Univ. Bengkulu.

Rachmawan, O. 2001. Pengeringan, Pendidikan Dan Pengemasan Komoditas Pertanian. Tim Program Keahlian Teknologi Hasil Pertanian, Jakarta.

Rahadian, 2009. Kalor Dan Perubahan Wujud. Pelajaran Fisika.

Yasar. M., Mustaqimah., R. Agustina., D. Nurba dan Mustaqimah. 2019. Modification and performance test of fish and keumamah dryer with solar energy sources. https://iopscience.iop.org/issue/1755-1315/365/1.

Zemansky. 2002. Kalor dan Termodinamika. Institut Pertanian Bogor. Jawa Barat. 